\title{
Invasion rate and population characteristics of the round goby Neogobius melanostomus: effects of density and invasion history
}

\author{
Farivar Azour ${ }^{1, *}$, Mikael van Deurs ${ }^{1,2}$, Jane Behrens $^{1}$, Henrik Carl $^{3}$, Karin Hüssy ${ }^{1}$, \\ Kristian Greisen ${ }^{3}$, Rasmus Ebert ${ }^{3}$, Peter Rask Møller ${ }^{3}$ \\ ${ }^{1}$ National Institute of Aquatic Resources (DTU Aqua), Technical University of Denmark, Jægersborg Allé 1, \\ 2920 Charlottenlund, Denmark \\ ${ }^{2}$ Department of Biology, Lund University, Sölvegatan 37, Lund, Sweden \\ ${ }^{3}$ Natural History Museum of Denmark, University of Copenhagen, Universitetsparken 15, 2100 Copenhagen Ø, Denmark
}

\begin{abstract}
Round goby Neogobius melanostomus is currently one of the most wide-ranging invasive fish species in Europe and North America. The present study demonstrates how the distribution of round goby has expanded from 2008 to 2013 at a rate of about $30 \mathrm{~km} \mathrm{yr}^{-1}$ along the Danish coastline in the western Baltic Sea. Further analyses showed that fish from an established high-density round goby population were slow-growing and displayed poorer condition (weight at age and hepatosomatic index) compared to fish sampled from recently invaded locations (i.e. at the forefront of the distribution range). The established population revealed a broad age distribution and a 1:1 gender ratio, while fish from a recently invaded site were primarily of intermediate ages with a male-biased gender ratio. Otolith analyses suggested that the oldest individuals from the recently invaded area experienced superior growth conditions only in the most recent years, suggesting immigration into the area as adults. Our results suggest that intraspecific competition for food may cause continued dispersal of the species and that population demographics likely relate to invasion history.
\end{abstract}

KEY WORDS: Range expansion · Density-dependent growth $\cdot$ HSI $\cdot$ Gender ratio $\cdot$ Otolith · Dispersal

\section{INTRODUCTION}

The round goby Neogobius melanostomus (Pallas, 1811) is a relatively small demersal fish originating from the Ponto-Caspian region. In a recent evaluation of 18 taxa of non-indigenous species in the Baltic Sea region, round goby was found to be among the most impactful species (Ojaveer \& Kotta 2014). Several studies have shown both harmful and beneficial effects on the native species. Round goby preys on the eggs of native fishes (Sapota 2005, Kornis et al.

${ }^{*}$ Corresponding author: f_azour@hotmail.com
2012) and is often superior in competition for food, shelter and spawning habitats (Lauer et al. 2004, Balshine et al. 2005, Karlson et al. 2007). Over time, however, the species has also become a major food item for several native piscivorous fish (Almqvist et al. 2010). In this context, there is a pressing need to understand the biology and ecology of this species in the Baltic region to predict the long-term effects of its presence on ecosystem structure and functioning.

Since its first occurrence in the Baltic Sea in 1990 (Gulf of Gdansk, central Baltic Sea; Skóra \& Stolarski restricted. Authors and original publication must be credited. 
1996), it has spread considerably in the region and occupied an area of about $270 \mathrm{~km}^{2}$ in 1997 and $400 \mathrm{~km}^{2}$ in 2001 (Sapota 2006). In 1999, the first specimens were caught by fishermen around Rügen Island in the western Baltic Sea (H. Winkler unpubl. data cited in Corkum et al. 2004), and in 2005, the species was reported in the northeastern parts of the Baltic Sea (Finland; E. Leppakoski \& H. Ojaveer pers. comm. reviewed in Sapota 2006). The first observations of round goby in southeastern Denmark were made in coastal waters of Bornholm in 2008 and Lolland-Falster in2009 (Møller \& Carl 2010). The spreading of this species between distant areas is presumably via ballast water related to increased global trade and transportation (Kornis et al. 2012). However, information about the predominant natural spreading mechanisms of this species is scarce, and no year-to-year observations of small-scale dispersal exist. Likewise, knowledge about population dynamics and demographics during the years after first colonization into pristine areas is limited.

The success of an interspecific competitor may result in fast growth and high densities soon after first colonization of a preferred area (Karlson et al. 2007), followed by depressed growth due to densitydependent intra-specific competition for limited food resources (Heath 1992, Lorenzen \& Engberg 2002, Lobon-Cervia 2007). Studies have furthermore suggested that plasticity in demographics is an important advantage among successful invasive species that allows the organism to adapt to different environments during various stages of an invasion (Bøhn et al. 2004, Brownscombe \& Fox 2012, Brandner et al. 2013a).

In the present study, we show how the round goby has gradually dispersed along the coastline of southeastern Denmark since first records of its sighting in 2008 and 2009. Population characteristics at a selected study site (Skælskør Fjord) on the forefront of the species distribution were compared to those of a well-established round goby population near the origin of the invasion (Guldborgsund) (see top left map in Fig. 1). Comparisons of growth, condition and demographics were conducted. We hypothesized that specimens from the more densely populated site with a longer invasion history have a lower growth rate and are in poorer condition compared to specimens from the site that was more recently invaded and had a less dense population. Additionally, we expected to find differences in population demographics, such as age and gender distribution, reflecting population plasticity in the different stages of the invasion process, as suggested by Bøhn et al. (2004) and Corkum et al. (2004).

\section{MATERIALS AND METHODS}

\section{Invasion history and dispersal rate}

Since the first round goby was observed in Bornholm, Denmark in 2008, its distribution has been closely monitored by the National Fish Atlas project (www.fiskeatlas.dk), a data collection program using bycatch data from local fishermen and collections with push nets, beach seines and snorkel surveys. The data collection program covered the entire coastline of Denmark but was more intensive in regions adjacent to where the round goby had been observed in previous years, as the focus was to monitor natural (without anthropogenic interference) alongcoast dispersal rates. In the current area of distribution, 275 snorkel surveys were conducted between 2008 and 2013, with 1 in 2008, 7 in 2009, 23 in 2010, 33 in 2011, 99 in 2012 and 112 in 2013. Snorkel surveys, push nets and beach seines covered shallow waters (0 to $5 \mathrm{~m})$, whereas information from local fishermen covered a wider depth range $(0$ to $10 \mathrm{~m})$, and all data were combined to create annual presence-absence maps. The dispersal rate $\left(\mathrm{km} \mathrm{yr}^{-1}\right)$ was calculated as the total distance between the population center in 2009 and the northern edge of the distribution in 2013, divided by 5 yr. As no pelagic larvae have been found in the Baltic, and since extensive trawl surveys in deeper waters have caught very few round gobies (ICES database), coastline distance was used, assuming that the spreading occurs along the coast in relatively shallow water.

\section{Study design and selection of study sites}

Two study sites were selected based on annual presence-absence data generated by the National Fish Atlas project: (1) a recently invaded site, Skælskør Fjord (referred to as 'Recently'), at the forefront of the species distribution (first observed in 2012); and (2) Guldborgsund (referred to as 'Established'), with a relatively long invasion history and a well-established round goby population (first observed in 2009). The 2 study sites were close (50 km apart, see Fig. 1) and similar in terms of depth, substratum and climatic conditions (Fig. 1). At the recently invaded study site, data were collected only in 2013 (Recently-2013) at a time when population density was estimated to be 0.01 fish $\mathrm{m}^{-2}$. From the established population, data were collected in 2010, 2012 and 2013 i.e. (Established-2010, -2012, -2013). In 2013, the population densities had reached a high of 1.9 fish $\mathrm{m}^{-2}$. 
The population densities mentioned above for Established-2013 and Recently-2013 were estimated based on daytime snorkel surveys. Three surveys were conducted for Recently-2013, each covering a distance of $500 \mathrm{~m}$, and all round gobies observed within a $1 \mathrm{~m}$ radius from the snorkeler were counted (i.e. $1000 \mathrm{~m}^{2}$ ). Because of a combination of logistics and technical problems, only 2 surveys were carried out for Established-2013, covering a distance of 143 and $150 \mathrm{~m}$, but we consider the results of the 2 surveys representative of the density based on experiences from the numerous surveys elsewhere. All surveys were conducted within a 3 wk period in September to October 2013. No 2 surveys were conducted on the same day in the same area, but on 1 occasion, both locations were surveyed on the same day. Each survey covered depths from 0.5 to $3 \mathrm{~m}$. Weather conditions were the same for all surveys (cloudy), and turbidity was always low (clear water).

\section{Specimen collection method}

Fish were caught with various gear types (handheld shrimp net, shrimp fyke net and eel traps) or provided by local fishermen using fyke traps. The diversity of gear types was necessary to ensure that all size classes (and hence ages) were adequately represented in the data sets. All fish were stored at $-20^{\circ} \mathrm{C}$ for later analysis.

\section{Length, weight, gender and hepatosomatic index}

All fish were processed 5 to $10 \mathrm{~d}$ after capture. In the laboratory, after thawing, individual fish were measured for total length (TL) to the closest $\mathrm{mm}$ and total body weight $(W)$ and liver weight $(H)$ to the nearest mg. For Established-2012, only $W$ was measured. Gender was determined by visual examination of the gonads. Immature fish without visible gonads were recorded as unknown sex. Detailed reproductive parameters might also be important when studying condition and growth in relation to dispersal of invasive species (e.g. Copp \& Fox 2007), but since our specimens were collected outside the spawning season, these parameters were not included here and will not be discussed any further. The hepatosomatic index (HSI) provides a good indication of energy reserves and is therefore a useful tool to evaluate general condition of an individual (Chellappa et al. 1995). HSI was determined for each fish using
HSI $=100 \times H \times W^{-1}$ (where $H$ is liver weight in grams, and $W$ is fish weight in grams) (Chellappa et al. 1995).

\section{Aging and reconstruction of growth histories based on otoliths}

Otolith analyses were carried out on a subset of fish from both study locations from 2013 (Established2013 and Recently-2013). Seven randomly chosen specimens from each length group (30 to $197 \mathrm{~mm}$ from Established-2013 and 43 to $173 \mathrm{~mm}$ from Recently-2013, length frequency was based on $10 \mathrm{~mm}$ TL classes) were selected. Some size classes contained fewer than 7 specimens. Otoliths were examined for 110 fish from Established-2013 and 50 fish from Recently-2013. Right and left sagittal otoliths from each individual were placed in black plastic trays used for routine otolith processing and soaked in $95 \%$ ethanol for approximately $5 \mathrm{~min}$. Otoliths were then viewed under a microscope equipped with a fixed circular light source from above, photographed with a camera (DFC290) and digitized using the Leica Application Suite.

The image analysis system Image J (1.47) (Abramoff et al. 2004) was used for image optimization and measurements. Contrast between otolith growth zones was enhanced using a local equalization filter. An annulus is defined as the translucent zone, often referred to as a winter zone or winter ring (Hüssy et al. 2012). The annuli were identified visually, and age was estimated by counting the annual rings. The longest axis of each otolith was measured, as were the distances between winter annuli from the center of the otoliths toward the ventral edge of the otolith. The distance between subsequent winter rings represents a proxy of the annual growth of the fish owing to the linear relationship between fish size and otolith size (Campana 1990). To reconstruct and compare growth histories in Established-2013 and Recently-2013, otolith size at previous ages was derived by summing annual growth increments of all previous years for each specimen.

\section{Statistical analyses}

In relation to statistical analyses, the 4 data sets (Recently-2013, Established-2013, Established-2012 and Established-2010) will be referred to as 'locations'. All analyses were carried out using R v.3.1.3 (R Development Core Team 2009). In all tests, $\alpha=0.05$ 
was used as the threshold of significance. To ensure a full overlap between locations in the fish length range, only fish between 100 and $170 \mathrm{~mm}$ were included. The effect of location on the length-weight relationship was tested by fitting a multiple linear regression model to the data. The length-weight relationship was linearized by a logarithmic transformation of $W$ and TL. The initial statistical model included main effects and interaction effects:

$\log W=a(\log \mathrm{TL})+b_{\text {Recently-2013,Established-2013,...(location) }}$

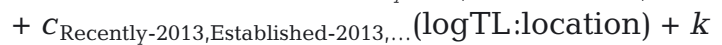

Location is a factor representing 4 levels, 1 for each location. The best model fit was obtained by stepwise elimination of parameters, where models were compared using the Bayesian information criterion and chi-square to test whether a reduction of model complexity leads to a significant reduction in the explanatory power. Standardized model residuals plotted against fitted values and quantile-quantile plots were inspected to ensure that a linear model was sufficient.

The ratio between males and females differed between locations. The effect of gender on the length-weight relationship was therefore first tested separately for Recently-2013, Established-2013 and Established-2010 (note that gender was not determined in Established-2012) to decide whether males and females should be pooled together. Difference in gender ratio between study sites was tested using Pearson's chi-squared test.

Differences in length-at-age between Recently2013 and Established-2013 were tested by estimating the main effects and interaction effects in the 2-way factorial ANOVA model

$\mathrm{TL}=a_{\text {age } 1, \text { age } 2, \ldots}$ (age) $+b_{\text {Recently-2013,Established-2013 (location) }}$

$+C_{\text {age 1:Recently-2013,age 1:Established-2013,...(age:location) }}$

where age has up to 4 levels (age 1, 2, 3 and 4; fish older than $4 \mathrm{yr}$ of age were excluded) and location has 2 levels (Recently-2013 and Established-2013). The model was fitted to females and males separately to avoid any confounding effects of gender (the data were too few and unbalanced to support a meaningful 3-way ANOVA model). Reduction of model complexity was carried out in the same way as for the length-weight model described previously.

Differences in mean HSI between Recently-2013, Established-2013 and Established-2010 were tested using a 1-way ANOVA and Student's t-test with Bonferroni correction for pairwise comparisons. Males and females were tested separately. Data from Established-2013, in contrast to the remaining data, contained many fish smaller than $75 \mathrm{~mm}(\mathrm{n}=99)$. These fish were excluded from the analysis. To avoid any further confounding effect of fish TL, the relationship between HSI and TL was tested for each dataset using linear regressions. These pre-tests confirmed that HSI was independent of TL.

In all tests, $\alpha=0.05$ was used as the threshold of significance.

\section{RESULTS}

\section{Invasion history and dispersal rate}

Since 2009, when the fish was observed in Guldborgsund (Established), the round goby has spread on average $30 \mathrm{~km} \mathrm{yr}^{-1}$ along the coastline, both eastward and westward, reaching Skælskør Fjord in 2012 (the location here referred to as Recently-2013). However, around Bornholm Island, where the first specimen was recorded in 2008, dispersal along the coastline was slower, ca. $10 \mathrm{~km} \mathrm{yr}^{-1}$ (Fig. 1).

\section{Specimen collection}

A total of 218 round gobies were collected in Recently-2013, 478 in Established-2010, 84 in Established-2012 and 500 in Established-2013. Details of numbers of fish caught, sampling dates, gear types and their technical details in relation to study site and year are presented in Table 1.

\section{Fish condition}

The initial length-weight model could not be further reduced (Table 2), indicating significant differences (i.e. different slopes and intercepts) between all locations (Recently-2013, Established-2013, Established-2012 and Established-2010). Both Recently-2013 and Established-2010 displayed greater weights at a given length compared to fish from Established-2012 and Established-2013, indicating that fish from areas with a short invasion history were in better condition (Fig. 2). There was no significant gender effect found for any of the locations, so data from males and females were pooled (Table 3).

HSI for male and females followed similar trends. HSI was highest in Recently-2013, followed by Established-2010, the differences being highly significant (all differences were significant, see Table 4). 


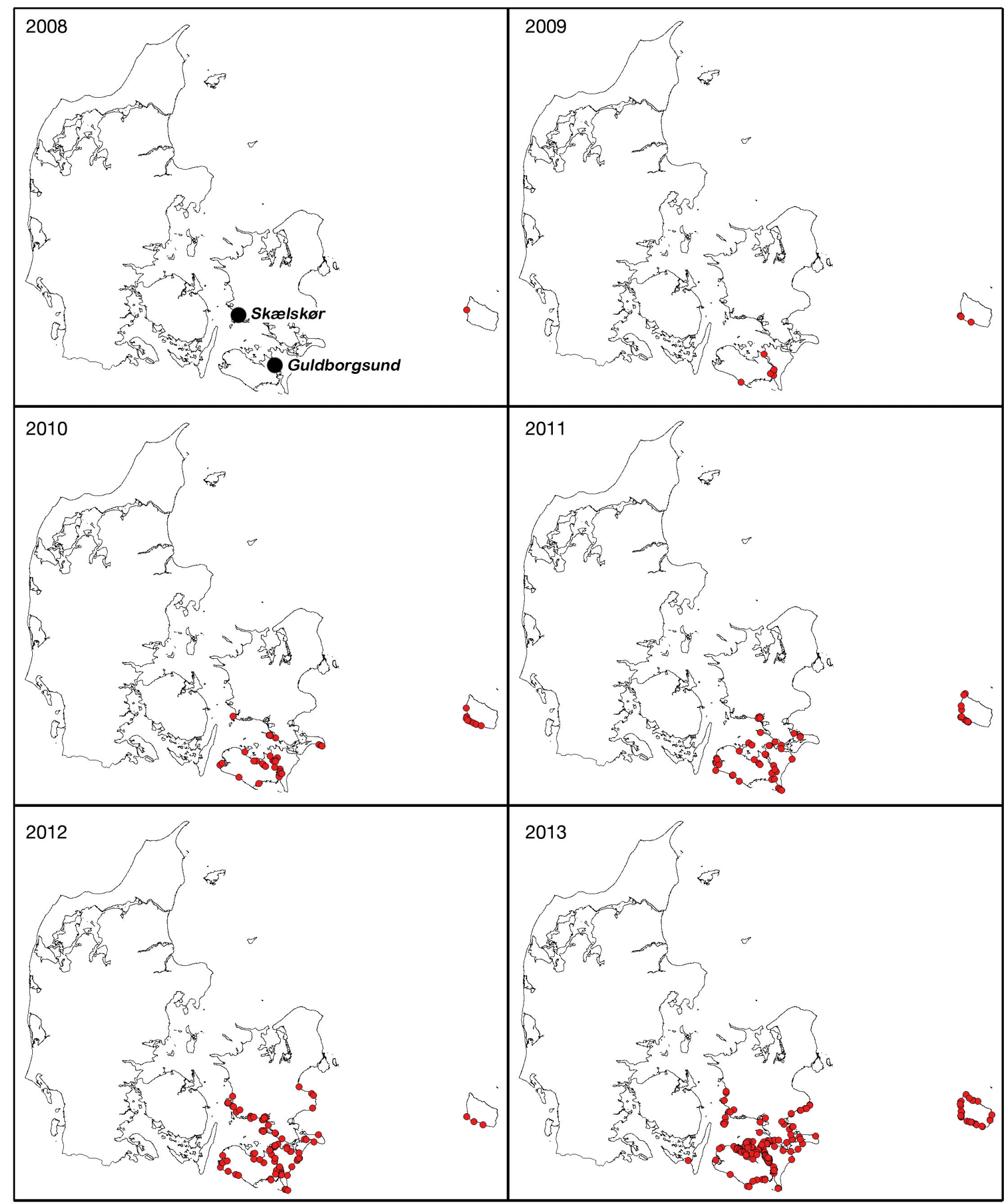

Fig. 1. Invasion history. Round goby occurrence from 2008 to 2013 in Danish waters, western Baltic Sea. Red dots indicate documented presence of round goby in a given year, i.e. maps are not cumulative. Black dots on the top left map indicate the 2 study sites: Guldborgsund (corresponds to the study site referred to as 'Established') and Skæelskør Fjord ('Recently'). Note that the first round goby observation in Danish waters was reported in 2008 from Bornholm Island (top left map) 
Table 1. Number of round goby caught, date of capture, gear used for catching and performed analyses for the 4 data sets (Guldborgsund in 2010, 2012, 2013 = Established-2010, Established-2012, Established-2013, respectively; Skælskør Fjord in 2013 = Recently-2013). L-W: length-weight; HSI: hepatosomatic index

\begin{tabular}{|c|c|c|c|c|}
\hline Sampling location & Date & Gear & $\begin{array}{c}\text { No. of } \\
\text { fish caught }\end{array}$ & Performed analyses \\
\hline \multirow[t]{3}{*}{ Recently-2013 } & October-November 2013 & Fyke net, mesh size: $11 \mathrm{~mm}$ & 198 & \multirow{3}{*}{$\begin{array}{l}\mathrm{L}-\mathrm{W}, \mathrm{HSI}, \text { age }(\mathrm{n}=50) \\
\text { gender }(\mathrm{n}=216) \\
\text { microstructure }(\mathrm{n}=11)\end{array}$} \\
\hline & October-November 2013 & Shrimp fyke net, mesh size: $5 \mathrm{~mm}$ & 18 & \\
\hline & October 2013 & Shrimp net, mesh size: $5 \mathrm{~mm}$ & 2 & \\
\hline \multirow[t]{2}{*}{ Established-2010 } & October-November 2010 & Fyke net, mesh size: $11 \mathrm{~mm}$ & 306 & \multirow{2}{*}{$\begin{array}{l}\text { L-W, HSI, gender } \\
(\mathrm{n}=478)\end{array}$} \\
\hline & October-November 2010 & Eel fyke net, mesh size: $11 \mathrm{~mm}$ & 172 & \\
\hline Established-2012 & October 2012 & Fyke net, mesh size: $11 \mathrm{~mm}$ & 84 & $\mathrm{~L}-\mathrm{W}$ \\
\hline \multirow[t]{3}{*}{ Established-2013 } & June-July 2013 & Fyke net, mesh size: $11 \mathrm{~mm}$ & 10 & \multirow{3}{*}{$\begin{array}{l}\mathrm{L}-\mathrm{W}, \mathrm{HSI}, \text { age }(\mathrm{n}=110) \\
\text { gender }(\mathrm{n}=400), \\
\text { microstructure }(\mathrm{n}=17)\end{array}$} \\
\hline & October 2013 & Fyke net, mesh size: $11 \mathrm{~mm}$ & 397 & \\
\hline & October-November 2013 & Shrimp net, mesh size: $5 \mathrm{~mm}$ & 93 & \\
\hline
\end{tabular}

Table 2. Comparison of different models using the Bayesian information criterion (BIC) (the BIC function in R was used) and chi-square to test if a reduction of model complexity leads to a significant reduction in the explanatory power relative to the full model (the ANOVA function in R was used). There is no $p$-value given for the model at the top of the table, as this is the full-complexity model that was compared pairwise to each of the reduced versions below. Square brackets indicate pooling and thus reducing the number of factors. For the full-complexity model (1st model): $F_{7,1047}=2561$, multiple $\mathrm{R}^{2}=0.94$

\begin{tabular}{|c|c|c|c|}
\hline Model & $\begin{array}{l}\text { Pooling of locations to reduce factor } \\
\text { levels }\end{array}$ & $\begin{array}{c}\mathrm{p} \\
\text { (chi-square) }\end{array}$ & $\mathrm{BIC}$ \\
\hline $\log ($ Weight $)=\log ($ Length $)+$ Location $+\log ($ Length $):$ Location & None & & -1810 \\
\hline Log $($ Weight $)=\log ($ Length $)$ & None & $<0.001$ & -1093 \\
\hline Log $($ Weight $)=\log ($ Length $)+$ Location & None & $<0.001$ & -1781 \\
\hline $\log ($ Weight $)=\log ($ Length $)+$ Location $+\log ($ Length $):$ Location & [Established-2013, Established-2012] & $<0.001$ & -1691 \\
\hline Log $($ Weight $)=\log ($ Length $)+$ Location $+\log ($ Length $):$ Location & [Established-2013, Established-2010] & $<0.001$ & -1781 \\
\hline $\log ($ Weight $)=\log ($ Length $)+$ Location $+\log ($ Length $):$ Location & [Established-2012, Established-2010] & $<0.001$ & -1402 \\
\hline $\log ($ Weight $)=\log ($ Length $)+$ Location $+\log ($ Length $):$ Location & $\begin{array}{l}\text { [Established-2013, Established-2012, } \\
\text { Established-2010] }\end{array}$ & $<0.001$ & -1234 \\
\hline
\end{tabular}

The interaction term in the initial age-length model was not significant for both males and females $(\mathrm{p}=$ 0.17 and $\mathrm{p}=0.41$, respectively, model comparison using chi-square), and the models were therefore reduced to include only the significant additive effects of locations (Table 5). Although we cannot be certain that fish from Recently-2013 have been growing faster throughout their entire life, these results underpin that growth conditions are superior at this recently invaded and still lightly populated location.

\section{Demographics}

Gender determination was possible in 400 of 500 fish in Established-2013 and in 216 of 218 fish in Recently-2013, resulting in a male:female ratio of $1: 1$ and 2.5:1, respectively. Male:female ratios significantly differed between sites $(p<0.01)$.

There were distinct demographic differences between study locations. Round gobies from Estab- lished-2013 ranged from 0 to $7 \mathrm{yr}$ of age, with a single male (fish length: $19.4 \mathrm{~cm}$ ) being the only $7 \mathrm{yr}$ old fish found. Ten 6 yr old fish (9 males and 1 female) were also found in Established-2013. Fish from Recently2013 were between 0 and 5 yr of age, although young fish (age 0 and age 1 ) were considerably rarer than in Established-2013 (Table 6).

\section{Reconstruction of growth histories from otoliths}

There were no significant differences in lengthat-age between the 2 study sites (Fig. 3). Round goby $\mathrm{TL}(\mathrm{mm})$ and otolith diameter $(\mathrm{mm})$ were linearly related, with no significant difference between areas (otolith length $=0.026 \times \mathrm{TL}+0.97, \mathrm{R}^{2}=0.97$ ), confirming that otolith size is an accurate proxy of fish length (Fig. 4).

Reconstruction of the early period required old fish, which were rare in Recently-2013; hence, only Established-2013 is presented in 2007 and 2008 (Fig. 5). 

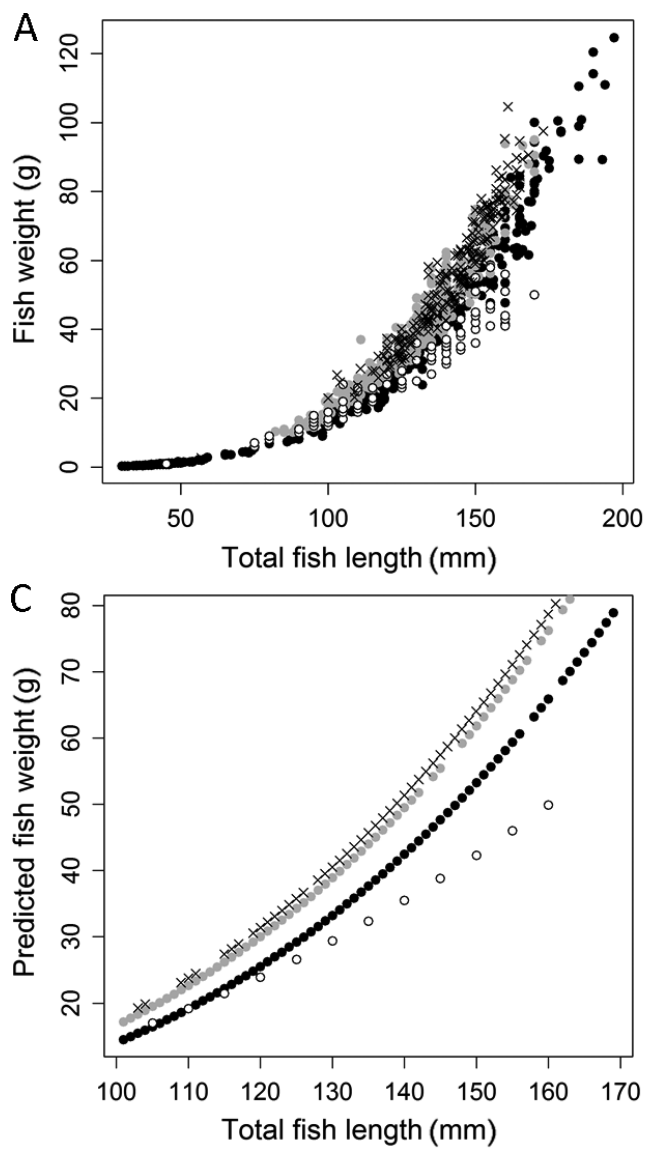

B

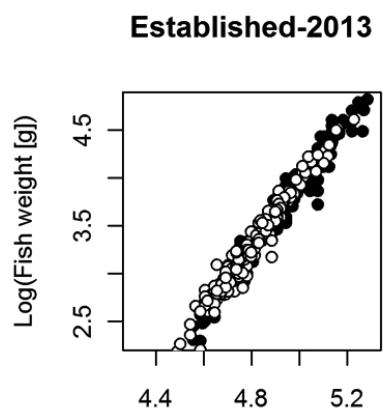

$\log ($ Total fish length $[\mathrm{mm}])$
Recently-2013

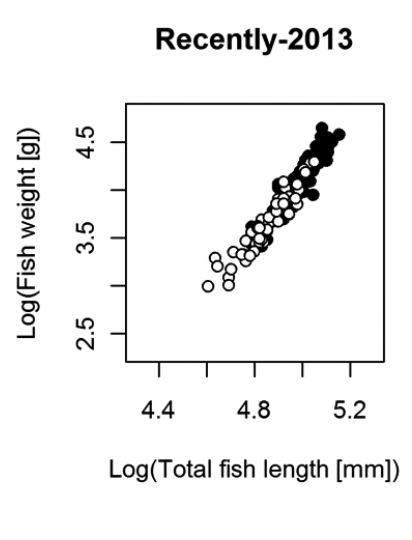

$\log ($ Total fish length $[\mathrm{mm}])$
Established-2010

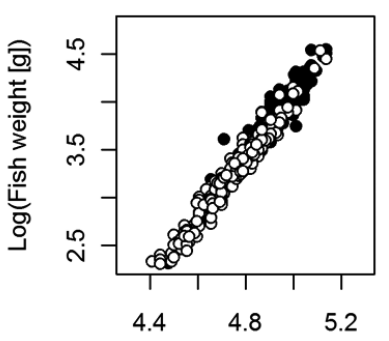

Log(Total fish length [mm])

Fig. 2. Effect of location on the lengthweight relationship in round goby. (A) Total fish length vs. fish weight for Recently-2013 (crosses), Established-2010 (grey), Established-2012 (white), Established-2013 (black). (B) Logarithmictransformed length-weight relationships for males (black) and females (white) for the 3 locations. (C) Predicted lengthweight relationship for Recently-2013 (crosses), Established-2010 (grey), Established-2012 (white), Established-2013 (black). Predictions were made using the full statistical model (see Table 2)

\section{DISCUSSION}

Table 3. Summary of the test statistics from multiple linear regression models fitted to data from each of the locations where the gender was determined: $\log W=a(\log T L)+g_{\text {female, male }}($ gender $)+a: g_{\text {female }} a: g_{\text {male }}(\log T L:$ gender) $+k$, where gender is a factor with 2 levels (females and males). Recently-2013: $F_{3,210}=870.1$; Established-2010: $F_{3,428}=2108$; Established-2013: $F_{3,342}=1917$. Note that only $g_{\text {male }}$ was estimated. This is because females were used as the baseline, and $g_{\text {male }}$ therefore is zero. The given values are p-values used to evaluate whether the estimated coefficient differed significantly from 0

\begin{tabular}{|llcrrr|}
\hline Location & Coeff. & $\begin{array}{c}\text { Estimated } \\
\text { value }\end{array}$ & SE & $t$ & $\mathrm{p}$ \\
& & & & \\
\hline \multirow{2}{*}{ Recently-2013 } & $k$ & -10.83 & 0.63 & -17.10 & $<0.001$ \\
& $a$ & 2.98 & 0.13 & 22.87 & $<0.001$ \\
& $g_{\text {male }}$ & -1.47 & 0.79 & -1.86 & 0.065 \\
& $a: g_{\text {male }}$ & 0.30 & 0.16 & 1.86 & 0.064 \\
Established-2010 & $k$ & -11.50 & 0.33 & -34.66 & $<0.001$ \\
& $a$ & 3.11 & 0.07 & 44.92 & $<0.001$ \\
& $g_{\text {male }}$ & -0.51 & 0.44 & -1.15 & 0.252 \\
& $a: g_{\text {male }}$ & 0.11 & 0.09 & 1.22 & 0.224 \\
Established-2013 & $k$ & -12.91 & 0.33 & -39.51 & $<0.001$ \\
& $a$ & 3.37 & 0.07 & 49.69 & $<0.001$ \\
& $g_{\text {male }}$ & 0.59 & 0.48 & 1.23 & 0.219 \\
& $a: g_{\text {male }}$ & -0.12 & 0.10 & -1.25 & 0.211 \\
\hline
\end{tabular}

\section{Invasion history and dispersal rate}

The expansion of round goby distribution in the southern Baltic is characterized by hotspots of high densities interspersed with areas of low densities. River estuaries and protected bays seem to be favorable sites for the round goby (Czugała \& Woźniczka 2010). The protected straight of Guldborgsund (Established) is now demonstrated to be another such hotspot, with a population density as high as 1.9 ind. $\mathrm{m}^{-2}$ in 2013. This is lower than other established localities in the Baltic Sea, e.g. Puck Bay near Gdansk (up to 3.4 ind. $\mathrm{m}^{-2}$ ) (Sapota \& Skora 2005). Much higher densities (up to 50 ind. $\mathrm{m}^{-2}$ ) are reported from freshwater systems (e.g. Charlebois et al. 1997, Vélez-Espino et al. 2010), probably because of earlier maturity and smaller size in freshwater compared to brackish water habitats (MacInnis \& Corkum 2000). 
Table 4. Summary of mean hepatosomatic index (HSI) ( \pm SE) and statistical comparison using ANOVA. Intercomparisons were carried out using Student's $t$-test and Bonferroni corrections

\begin{tabular}{|lcccc|}
\hline & Established-2010 & Established-2013 & Recently-2013 & $\mathrm{p}$ \\
\hline HSI females & $5.03( \pm 0.074)$ & $4.37( \pm 0.088)$ & $5.89( \pm 0.075)$ & $<0.001$ \\
Established-2010 & - & $\mathrm{p}<0.001$ & $\mathrm{p}<0.001$ & - \\
Established-2013 & - & - & $\mathrm{p}<0.001$ & - \\
HSI males & $4.74( \pm 0.062)$ & $3.34( \pm 0.087)$ & $5.23( \pm 0.138)$ & $<0.001$ \\
Established-2010 & - & $\mathrm{p}<0.001$ & $\mathrm{p}<0.001$ & - \\
Established-2013 & - & - & $\mathrm{p}<0.001$ & - \\
\hline
\end{tabular}

Table 5. Summary of the test statistics of the reduced model: TL $=$

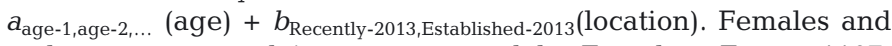
males were treated in separate models. Females: $F_{4,52}=1107$; males: $F_{5,49}=1410$. Note that only $b_{\text {Established-2013 }}$ is estimated. This is because Recently-2013 is used as the baseline, and $b_{\text {Recently-2013 }}$ therefore is zero. This also means that the estimated a-coefficients correspond to mean TL for each age class in Recently-2013. The given values are p-values used to evaluate whether the estimated coefficient differed significantly from 0

\begin{tabular}{|lccccc|}
\hline Model & Coefficient & $\begin{array}{c}\text { Estimated } \\
\text { value }\end{array}$ & SE & $t$ & $\mathrm{p}$ \\
\hline Females & $a_{\text {age1 }}$ & 110.36 & 3.704 & 29.796 & $<0.001$ \\
Females & $a_{\text {age2 }}$ & 128.394 & 3.227 & 39.791 & $<0.001$ \\
Females & $a_{\text {age3 }}$ & 164.152 & 7.636 & 21.497 & $<0.001$ \\
Females & $b_{\text {Established-2013 }}$ & -10.152 & 3.772 & -2.691 & 0.01 \\
Males & $a_{\text {age1 }}$ & 97.242 & 5.55 & 17.521 & $<0.001$ \\
Males & $a_{\text {age2 }}$ & 141.998 & 2.918 & 48.66 & $<0.001$ \\
Males & $a_{\text {age3 }}$ & 159.103 & 3.935 & 40.437 & $<0.001$ \\
Males & $a_{\text {age4 }}$ & 168.766 & 4.704 & 35.88 & $<0.001$ \\
Males & $b_{\text {Established-2013 }}$ & -8.282 & 3.506 & -2.363 & 0.0222 \\
\hline
\end{tabular}

It took 19 yr from the first round goby observation in the Gulf of Gdansk (central Baltic Sea) until its arrival in Guldborgsund, a distance of 500 to $600 \mathrm{~km}$. This rate of range expansion corresponds well with the ca. $30 \mathrm{~km} \mathrm{yr}^{-1}$ found along the Danish coastline and with modeled rates for highly mobile specimens in Canadian rivers (Brownscombe et al. 2012). The estimated rate of expansion is, however, lower than rates reported in Grosholz (1996) (ca. $50 \mathrm{~km} \mathrm{yr}^{-1}$ ), which may be explained by the nest-guarding behavior (Jude 1997, Karlson et al. 2007) and short nocturnal pelagic larval phase of round gobies (Hensler \& Jude 2007). In the Baltic Sea, the round goby is mainly associated with relatively shallow waters (depth <20 m) (Kullander \& Delling 2012), but it is known to be capable of crossing waters as deep as 50 to $60 \mathrm{~m}$ (Kottelat \& Freyhof 2007), indicating that depth is likely no barrier for dispersal in the Baltic Sea.

\section{Growth and condition}

Density-dependent life history processes are well documented in many fish species (e.g. Jenkins et al. 1999, Carol et al. 2009, Hazlerigg et al. 2012). Bøhn et al. (2004) demonstrated that life history traits and somatic growth rates of fish can vary over the course of an invasion. In the early stages of an invasion, where densities are low, intraspecific competition for resources is expected to be limited. As density increases, so does the likelihood of intraspecific competition for resources such as food and nesting habitat, leading to decreased growth rates at population (i.e. number of specimens in a population) and individual levels (Bøhn et al. 2004). The present results document the reduced growth and condition (weight-length relationship and HSI) of round goby in a well-established high-density population (1.9 ind. $\mathrm{m}^{-2}$; Established-2013) compared to the same area just 1 yr after the round goby was observed for the first time (Established-2010) and a recently invaded area with a density nearly 200 times lower (Recently-2013). Studies from other

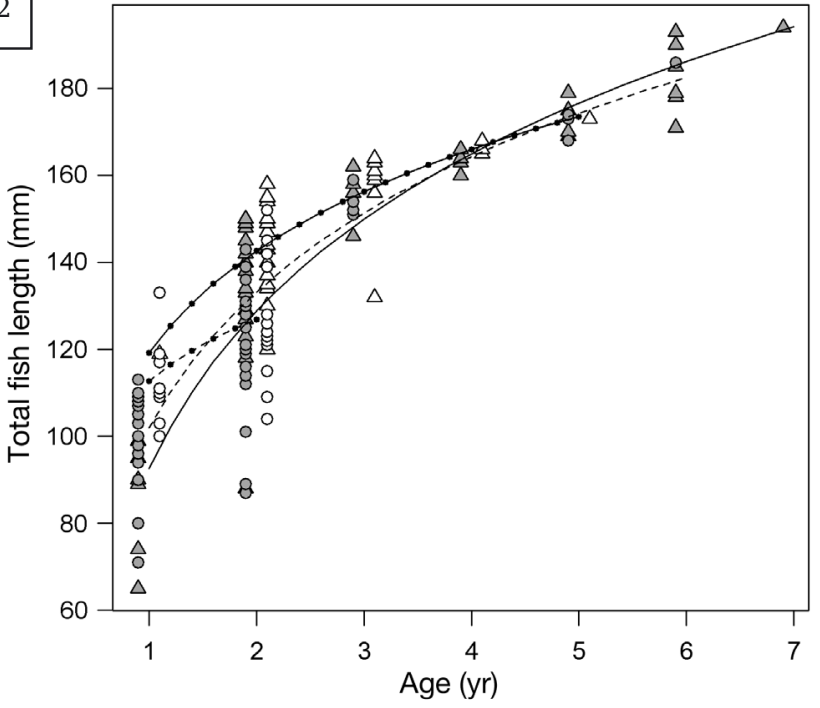

Fig. 3. Growth. Age-length relationships for females in Recently-2013 (white circles, dashed-dotted trend line), males in Recently-2013 (white triangles, solid-dotted trend line), females in Established-2013 (grey circles, dashed line) and males in Established-13 (grey triangles, solid line). Trend lines are fitted using a logarithmic function: $y=a \times \log (x)+b$ 
Table 6. Age distribution in the 2 study sites in 2013

\begin{tabular}{|c|c|c|c|c|c|c|c|c|c|c|c|c|}
\hline \multirow{3}{*}{$\begin{array}{l}\text { Length class } \\
\text { (mm TL) }\end{array}$} & \multirow{2}{*}{\multicolumn{6}{|c|}{ Established-2013 }} & \multirow{2}{*}{\multicolumn{6}{|c|}{ Recently-2013 }} \\
\hline & & & & & & & & & & & & \\
\hline & 0 & 1 & 2 & 3 & 4 & $4+$ & 0 & 1 & 2 & 3 & 4 & $4+$ \\
\hline $30-70$ & 25 & 2 & & & & & 2 & & & & & \\
\hline $71-110$ & & 22 & 4 & & & & & 4 & 2 & & & \\
\hline $111-150$ & & & 26 & 1 & & & & 5 & 21 & 1 & & \\
\hline $151-190$ & & & & 7 & 4 & 16 & & & 3 & 7 & 4 & 1 \\
\hline $191-200$ & & & & & & 3 & & & & & & \\
\hline
\end{tabular}

results deviate from expectations. Fish from the established population had a significantly lower weight at length in 2012 compared to 2013. Various mechanisms may explain this, e.g. natural variability in temperature, with higher temperature favoring enhanced growth (Buckel et al. 1995) or interannual variation in food abundance. Alternatively, the explanation might be variations in life history traits, such as increased allocation of energy to reproduction, that typically occur during the progressing

areas also showed that specimens in newly invaded areas are in significantly better condition (Young et al. 2010, Gutowsky \& Fox 2011, 2012, Brandner et al. 2013b). For example, round gobies from a newly invaded section of Danube River areas had higher HSI values (indicating better condition) compared to specimens from older and more established populations in the same river (Brandner et al. 2013b). A study on diet composition of round goby in its expansion phase in the Trent-Severn Waterway (Ontario, Canada) demonstrated lower gut content in a well-established population compared to at the edge of their expansion (Raby et al. 2010), suggesting that densitydependent limitation of consumption is in fact the driving force for the observed reduction in condition. In one respect, however, the present

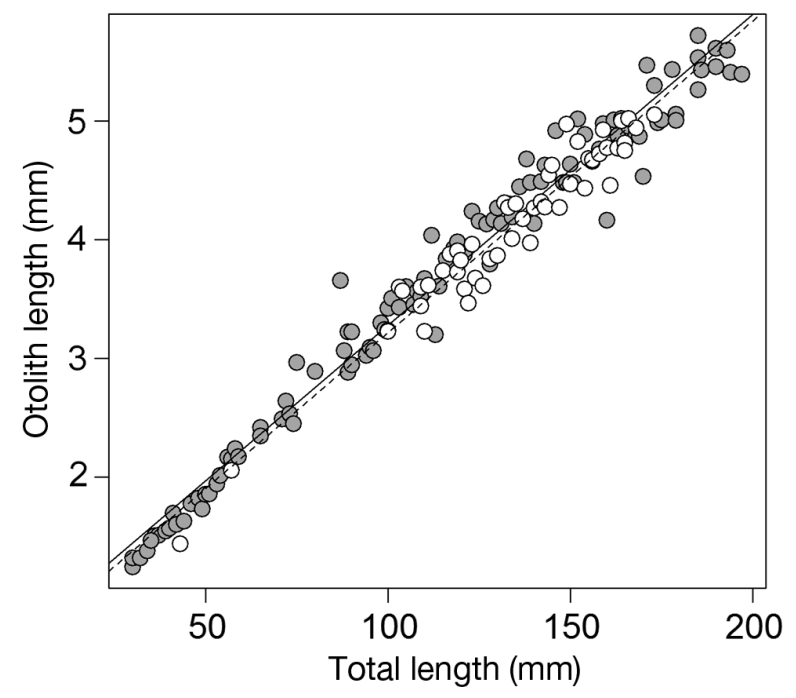

Fig. 4. Relationship between total fish length and otolith size (longest diameter of the otolith) in Established-2013 (grey circles) and Recently-2013 (white circles). Superimposed trend lines are fitted using linear regression analyses $\left(\mathrm{R}^{2}\right.$ Established-2013 $=0.97, \mathrm{R}^{2}$ Recently-2013 $=0.94$ ) invasion (Gutowsky \& Fox 2012, Hôrková \& Kováč 2015). These variations, however, are presumably related to density as well. Sex-specific difference in length distribution, with males slightly larger than females, is in accordance with earlier studies (MacInnis \& Corkum 2000, Sokołowska \& Fey 2011, Grul'a et al. 2012).

\section{Demographics}

The established population revealed a broad age distribution, with both younger and older individuals present, while mainly intermediate age classes were found at the recently invaded site together with a strongly male-biased gender ratio. The 1:1 male: female ratio in the established population is in contrast with most previous studies reporting male dominance (Grul'a et al. 2012, Gutowski \& Fox 2012, Brandner et al. 2013b), with ratios up to 6:1 occurring in the Laurentian Great Lakes, where round goby have occurred since 1993 (Gutowski \& Fox 2012). Gender ratios in recently invaded areas are less studied, with 2 recent studies, however, reporting female dominance at the invasion front in the Danube River and Trent-Severn Waterway (Ontario, Canada) (Brandner et al. 2013b, Brownscombe \& Fox 2012), thus contradicting the present findings of male dominance in the recently invaded area. Brownscombe \& Fox (2012) argued that female dominance at invasion fronts may be caused by males investing more energy in territorial defense and parental care than females. Thus, sex-biased dispersal by females serves as a possible strategy to reduce intraspecific competition for mates among females. Nevertheless, a recent study has revealed that male round goby moved further away from home sites than females (Marentette et al. 2011), and this could potentially explain why more males were caught in the recently invaded area in the present study. 
Age 1

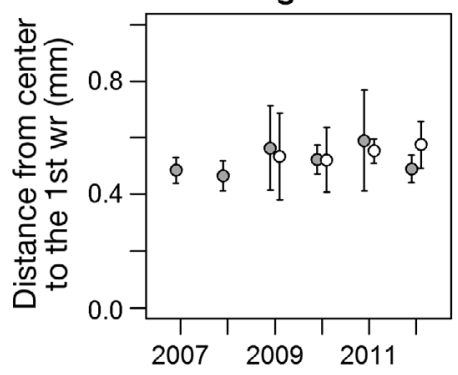

Age 3

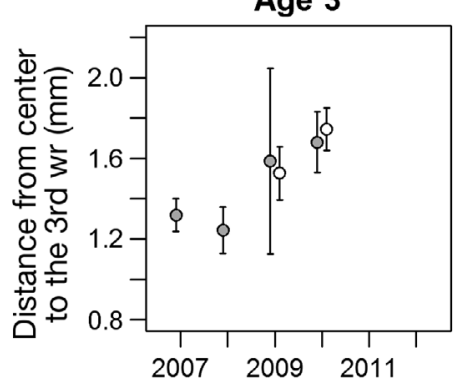

Age 2

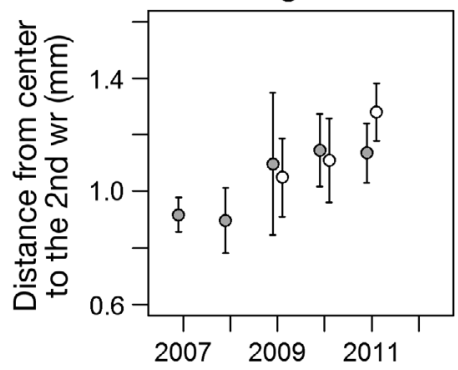

Age 4

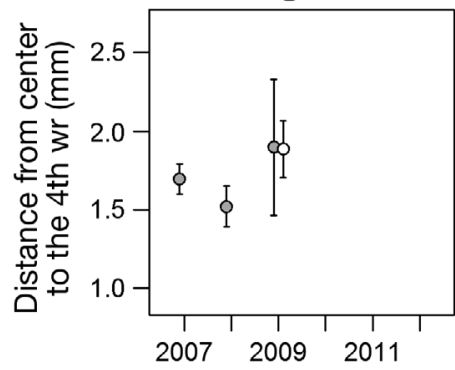

Fig. 5. Reconstruction of growth histories based on otoliths. The distance from the center of the otolith to the 1st, 2nd, 3rd and 4th winter ring (wr) was used as a proxy for the size of the fish in the past when it was 1, 2, 3 and 4 yr old, respectively. Grey circles are Established-2013, and white circles are Recently-2013. Circles are positioned along a time line indicating the year of birth for each fish, e.g. the grey circle above 2011 in the upper left panel indicates the mean otolith size of a 1 yr old fish born in 2011, assuming no size-selective mortality has taken place between 2011 and 2013. Reconstruction of the early period required old fish, which were rare in Recently-2013; hence, only Established-2013 is represented in 2007 and 2008. Whiskers represent 2 times the standard error of the mean (all mean values were based on 3 or more individuals)

The $7 \mathrm{yr}$ old round goby found in the present study (in Established-2013) is to our knowledge the oldest specimen recorded to date, where round goby of up to $6 \mathrm{yr}$ have been found in the southern Baltic Sea (Gulf of Gdansk) (Sokołowska \& Fey 2011). Together, this supports earlier observations that round goby have a longer lifespan in the brackish Baltic region compared to freshwater specimens from the Laurentian Great Lakes Basin and the Ponto-Caspian area, where maximum reported age is $4 \mathrm{yr}$ (MacInnis \& Corkum 2000, Sokołowska \& Fey 2011). Sokołowska \& Fey (2011) argued that this likely is a result of more favorable conditions and a vacant ecological niche in the brackish water, including food resources, suitable habitats and spawning grounds.

It is interesting that 9 of ten 6 yr old fish were males. Although purely speculative, this may suggest the potential for longer life span for males compared to females. Furthermore, since male round gobies reach

maturity at the age of 3 to $4 \mathrm{yr}$ (Charlebois et al. 1997, Sapota 2006), this finding also challenges the idea that male round gobies die after the end of spawning and nest guarding (Charlebois et al. 1997).

\section{Reconstruction of growth histories}

Reconstruction of growth histories from annual increments in otoliths indicated that the oldest individuals from the recently invaded area had experienced superior growth conditions only in the most recent years, indicating immigration into the area as adults from an adjacent area with (poorer) growth conditions similar to those experienced in the established population. However, reconstructed growth histories also indicated that fish from the older cohorts (2006 and 2007) had pronounced lower growth rates at the first and second years of life compared to the younger cohorts. This observation indicates that size-specific mortality occurs with lower mortality rates for slow growers. It may be that this is related to a trade-off between foraging and risk of being an object of predation (Titus \& Mosegaard 1991), where increased foraging leads to faster growth but also increased probability of being spotted by predators including fishermen. This fits well with the aggressive behavior of round goby; fast growth leads to relatively larger body size, which is an advantage in defending territory, chasing competitors and parental caretaking, but the impetuous behavior may also increase the risk of natural mortality due to increased predation.

\section{CONCLUSIONS}

The present study demonstrates how the distribution of round goby has expanded at a rate of ca. $30 \mathrm{~km}$ $\mathrm{yr}^{-1}$ along the Danish coastline in the western Baltic Sea. Furthermore, specimens from an established high-density population were slow-growing and displayed insignificantly lower condition compared to fish from the same site $3 \mathrm{yr}$ earlier $(1 \mathrm{yr}$ after the first observation of the species in the area) and from the more recently invaded site. A broad age distribution, with both younger and older individuals well represented, likewise characterized the established population. In contrast, mainly intermediate age classes dominated in the recently invaded area, together with a strongly male-biased gender ratio. Lastly, reconstruction of growth histories indicated that the oldest 
individuals from the recently invaded area had experienced superior growth conditions only in the most recent years, suggesting immigration into the new area as adults.

In various places in Europe and North America, round goby populations continuously expand their distribution by different invasion pathways. The present findings add valuable knowledge about potential factors driving dispersal and how different stages of an invasion process relate to population demographics. Overall, such knowledge is important as a mean to understand invasion patterns not only by the round goby but also by other invasive species and thus helps to predict potential consequences of such events.

Acknowledgements. This study was financially supported by the Danish AgriFish Agency, Aage V. Jensens Fonde, the Nordic Councils of Ministers and DFF-4002-00114. The authors are indebted to M. Krag and K. Wendelin (Natural History Museum of Denmark) and to T. Warner (Taastrup Gymnasium) for assisting with field work and to local fishermen at Guldborgsund and Skælskør for supplying round gobies.

\section{LITERATURE CITED}

Abramoff MD, Magalhaes PJ, Ram SJ (2004) Image processing with ImageJ. Biophoton Int 11:36-42

Almqvist G, Strandmark AK, Appelberg M (2010) Has the invasive round goby caused new links in Baltic food webs? Environ Biol Fishes 89:79-93

Balshine S, Verma A, Chant V, Theysmeyer T (2005) Competitive interactions between round gobies and logperch. J Gt Lakes Res 31:68-77

Bøhn T, Sandlund OT, Amundsen PA, Primicerio R (2004) Rapidly changing life history during invasion. Oikos 106: 138-150

Brandner J, Auerswald K, Cerwenka AF, Schliewen UK, Geist J (2013a) Comparative feeding ecology of invasive Ponto-Caspian gobies. Hydrobiologia 703:113-131

Brandner J, Cerwenka AF, Schliewen UK, Geist J (2013b) Bigger is better: characteristics of round gobies forming an invasion front in the Danube River. PLoS ONE 8: e73036

> Brownscombe JW, Fox MG (2012) Range expansion dynamics of the invasive round goby (Neogobius melanostomus) in a river system. Aquat Ecol 46:175-189

Brownscombe JW, Masson L, Beresford DV, Fox MG (2012) Modeling round goby Neogobius melanostomus range expansion in a Canadian river system. Aquat Invas 7: 537-545

> Buckel JA, Steinberg ND, Conver DO (1995) Effects of temperature, salinity, and fish size on growth and consumption of juvenile bluefish. J Fish Biol 47:696-706

- Campana SE (1990) How reliable are growth back-calculations based on otoliths? Can J Fish Aquat Sci 47:2219-2227

Carol J, Benejam L, Benito J, Garcia-Berthou E (2009) Growth and diet of European catfish (Silurus glanis) in early and late invasion stages. Hydrobiologia 174:
$317-328$

Charlebois PM, Marsden JE, Goettel RG, Wolfe RK, Jude DJ, Rudnika S (1997) The round goby Neogobius melanostomus (Pallas). A review of European and North American literature. Ill Nat Hist Surv Spec Publ 20, Prairie Research Institute, Champaign, IL

Chellappa S, Huntingford FA, Strang RHC, Thomson RY (1995) Condition factor and hepatosomatic index as estimates of energy status in male three-spined stickleback. J Fish Biol 47:775-787

Copp GH, Fox MG (2007) Growth and life-history traits of introduced pumpkinseed (Lepomis gibbosus) in Europe, and the relevance to potential invasiveness. In: Gherardi $\mathrm{F}$ (ed) Biological invaders in inland waters: profiles, distribution, and threats. Springer, Dordrecht, p 289-306

Corkum LD, Sapota MR, Skóra KE (2004) The round goby, Neogobius melanostomus, a fish invader on both sides of the Atlantic Ocean. Biol Invasions 6:173-181

Czugała A, Woźniczka A (2010) The River Odra estuary another Baltic Sea area colonized by the round goby Neogobius melanostomus Pallas, 1811. Aquat Invasions 5:S61-S65

> Grosholz ED (1996) Contrasting rates of spread for introduced species in terrestrial and marine systems. Ecology 77:1680-1686

Grul'a D, Balážová M, Copp HG, Kováč V (2012) Age and growth of invasive round goby Neogobius melanostomus from middle Danube. Cent Eur J Biol 7:448-459

Gutowsky LFG, Fox MG (2011) Occupation, body size, and sex ratio of round goby (Neogobius melanostomus) in established and newly invaded areas in an Ontario river. Hydrobiologia 671:27-37

> Gutowsky LFG, Fox MG (2012) Intra-population variability of life history traits and growth during range expansion of the invasive round goby (Neogobius melanostomus). Fish Manag Ecol 19:78-88

> Hazlerigg CRE, Lorenzen K, Thorbek P, Wheeler JR, Tyler CR (2012) Density-dependent processes in the life history of fishes: evidence from laboratory populations of zebrafish Danio rerio. PLoS ONE 7:e37550

Heath MR (1992) Field investigations of the early life stages of marine fish. Adv Mar Biol 28:1-174

Hensler SR, Jude DJ (2007). Diel vertical migration of round goby larvae in the Great Lakes. J Gt Lakes Res 33: 295-302

Hôrková K, Kováč V (2015) Ontogenetic phenomena, temporal aspect, and ecological factors in the successful invasion of round goby Neogobius melanostomus in the River Danube. Aquat Invasions 10:227-235

> Hüssy K, Coad JO, Farrell ED, Clausen LAW, Clarke MW (2012) Age verification of boarfish (Capros aper) in the northeast Atlantic. ICES J Mar Sci 69:34-40

> Jenkins TM, Diehl S, Kratz WK, Cooper SD (1999) Effects of population density on individual growth of brown trout in streams. Ecology 80:941-956

Jude DJ (1997) Round gobies: cyberfish of the third millennium. Gt Lakes Res Rev 3:27-34

Karlson AML, Almqvist G, Skora KE, Appelberg M (2007) Indications of competition between non-indigenous round goby and native flounder in the Baltic Sea. ICES J Mar Sci 64:479-486

Kornis MS, Mercado-Silva N, Vander Zanden MJ (2012) Twenty years of invasion: a review of round goby (Neogobius melanostomus) biology, spread and ecological implications. J Fish Biol 80:235-285 
Kottelat M, Freyhof J (2007) Handbook of European freshwater fishes. Kottelat, Cornol and Freyhof, Berlin

Kullander SO, Delling B (2012) Ryggsträngsdjur: strålfeniga fiskar, Chordata: Actinopterygii. Nationalnyckeln till Sveriges flora och fauna. ArtDatabanken, Sveriges Lantbruksuniversitet, Uppsala

Lauer TE, Allen PJ, McComish TS (2004) Changes in mottled sculpin and johnny darter trawl catches after the appearance of round gobies in the Indiana waters of Lake Michigan. Trans Am Fish Soc 133:185-189

Lobon-Cervia J (2007) Density-dependent growth in streamliving brown trout Salmo trutta L. Funct Ecol 21:117-124

Lorenzen K, Engberg K (2002) Density-dependent growth as a key mechanism in the regulation of fish populations: evidence from among-population comparisons. Proc R Soc B 269:49-54

MacInnis AJ, Corkum LD (2000) Fecundity and reproductive season of the round goby Neogobius melanostomus in the upper Detroit River. Trans Am Fish Soc 129: 136-144

Marentette JR, Wang G, Tong S, Sopinka NM, Taves MD, Koops MA, Balshine S (2011) Laboratory and field evidence of sex-biased movement in the invasive round goby. Behav Ecol Sociobiol 65:2239-2249

Møller PR, Carl H (2010) Atlas over Danske saltvandsfisk. Dyr i Natur og Museum 1:14-17

Ojaveer H, Kotta J (2014) Ecosystem impacts of the widespread non-indigenous species in the Baltic Sea: literature survey evidences major limitations in knowledge. Hydrobiologia 750:171-185

Raby G, Gutowsky L, Fox M (2010) Diet composition and consumption rate in round goby (Neogobius melanostomus) in its expansion phase in the Trent River, Ontario. Environ Biol Fishes 89:143-150

Editorial responsibility: Roderick Finn, Bergen, Norway
R Development Core Team (2009) R: a language and environment for statistical computing. R Foundation for Statistical Computing, Vienna

Sapota MR (2005) Biology and ecology of round goby Neogobius melanostomus (Pallas 1811), invasive species in the Gulf of Gdańsk. University of Gdańsk (in Polish with English summary)

Sapota MR (2006) NOBANIS-invasive alien species fact sheet. Neogobius melanostomus. www.nobanis.org/files/ factsheets/Neogobius_melanostomus.pdf

Sapota MR, Skora K (2005) Spread of alien (nonindigenous) fish species Neogobius melanostomus in the Gulf of Gdansk (south Baltic). Biol Invasions 7:157-164

Skóra KE, Stolarski J (1996) Neogobius melanostomus (Pallas 1811) a new immigrant species in Baltic Sea. In: Styczynska-Jurewicz E (ed) Estuarine ecosystems and species, Proc 2nd Int Estuary Symp, Gdańsk, 18-22 October 1993. Iss Mar Biol Centre Gdynia 1:101-108

Sokołowska E, Fey DP (2011) Age and growth of the round goby Neogobius melanostomus in the Gulf of Gdańsk several years after invasion. Is the Baltic Sea a new Promised Land? J Fish Biol 78:1993-2009

> Titus RG, Mosegaard H (1991) Selection for growth potential among migratory brown trout (Salmo trutta) fry competing for territories: evidence from otoliths. Can J Fish Aquat Sci 48:19-27

Vélez-Espino LA, Koops MA, Balshine S (2010) Invasion dynamics of round goby (Neogobius melanostomus) in Hamilton Harbour, Lake Ontario. Biol Invasions 12: 3861-3875

Young JAM, Marentette JR, Gross C, McDonald JI, Verma A (2010) Demography and substrate affinity of the round goby (Neogobius melanostomus) in Hamilton Harbour. J Gt Lakes Res 36:115-122

Submitted: November 14, 2014; Accepted: May 7, 2015 Proofs received from author(s): July 4, 2015 